\title{
AVALIAÇÃO DA PARTIDA DE UM SISTEMA ANAERÓBICO NA REMOÇÃO DE MATÉRIA ORGÂNICA DE EFLUENTES LÍQUIDOS DE SUINOCULTURA
}

Claudionor Camilo da Costa - Professor do Instituto Federal de Minas Gerais - Campus São João Evangelista, CEP 39705-000, São João Evangelista-MG, claudionor.costa@ifmg.edu.br

Cláudio Milton Montenegro Campos - Professor DEG/UFLA, CEP 37200-000, Lavras-MG, cmmcampos@ufla.br

Fátima Conceição Rezende - Professora DEG/UFLA, CEP 37200-000, Lavras-MG, frezende@ufla.br

Luiz Fernando Coutinho de Oliveira - Professor DEG/UFLA, CEP 37200-000, Lavras-MG, lfco@pq.cnpq.br

\section{RESUMO}

Objetivou-se, com a realização deste trabalho, avaliar a partida de reatores anaeróbios em série na remoção de matéria orgânica de dejetos de suinocultura. A estação-piloto de tratamento de dejetos foi composta por caixa de areia, medidor de vazão Thompson, peneira estática, dorna de 8.500 litros, sistema de bombeamento, dois reatores anaeróbios sequenciais, sendo o primeiro reator, do tipo anaeróbico compartimentado (RAC) e o segundo, um reator do tipo anaeróbico de fluxo ascendente de manta de lodo (UASB). O reator anaeróbio compartimentado (RAC) mostrou, inicialmente, elevada eficiência na remoção de $\mathrm{DBO}_{5}$, devido, principalmente, ao efeito de decantação de sólidos em função da baixa carga superficial aplicada ao mesmo. Posteriormente, a eficiência chegou até o valor mínimo, aproximadamente $23 \%$, para, mais tarde, se elevar até $80 \%$ novamente. O reator UASB, ao contrário do RAC, demonstrou eficiência em torno de 45\% durante o início do experimento. Em seguida, porém, manteve certa estabilidade com eficiência aproximada de $80 \%$, para posterior queda (inferior a $40 \%$ ). Um dos motivos da queda, possivelmente, está relacionado com a temperatura ambiente.

Palavras-chave: RAC, UASB, dejetos de suínos, efluentes

\section{START-UP EVALUATION OF ANAEROBIC SYSTEM REMOVING ORGANIC MATTER OF SWINE WASTEWATER}

\section{ABSTRACT}

This research was carried out in order to evaluate the start-up of anaerobic reactors working in series removing organic matter of swine wastewater. The pilot system was assembled with a sand retention unit, Thompson flow rate meter, static screen, an equalization acidification tank (EAT) with 8,500 liters, pumping system, two sequencing anaerobic reactors, being the first unit an anaerobic baffled reactor (ABR) and, the second one, an upflow anaerobic sludge blanket reactor (UASB). The ABR showed at the beginning a higher efficiency in removing BOD, mainly due to the solids settling caused by the low superficial loading rate. Latter the efficiency reached the lowest value, about $23 \%$, and after a short period the efficiency went up to $80 \%$. The UASB in the other hand, showed efficiency about $45 \%$ at the beginning of the research, however, it maintained high stability with efficiency near to $80 \%$. Latter the efficiency decreased to values lower than $40 \%$. One of the reasons for this abrupt drop was due to the lowering of the environmental temperature.

Key words: ABR, UASB, swine manure, effluents

\section{INTRODUÇÃO}

Até a década de 1970 a densidade de animais na suinocultura proporcionava ageração de dejetos capaz de ser absorvida pelo solo, não constituindo em graves problemas. Com a evolução da suinocultura, 
os animais passaram a ser confinados em densidades cada vez maiores, aumentando a quantidade de dejetos produzidos, transformando em um importante agente impactante. Além disso, o confinamento ocasionou um aumento crescente no uso de água de higienização (lavação), aumentando o volume de dejetos e sua diluição (Oliveira, 1997).

O potencial poluente dos dejetos de suínos, em termos comparativos, é muito superior à de outras espécies. Os reatores anaeróbios de fluxo ascendente são uma boa opção no tratamento desses dejetos, principalmente em locais onde o custo da terra é alto podendo inviabilizar o uso de lagoas de estabilização que demandam grandes áreas (Chernicharo,1997).

Segundo Campos(1990), oreatoranaeróbio de fluxo ascendente de manta de lodo (upflow anaerobic sludge blanket reactor - UASB) foi inicialmente desenvolvido e aplicado largamente na Holanda. Essencialmente, o processo consiste de um fluxo ascendente de efluente que passa através de um lodo denso e de elevada atividade. O perfil de sólidos no reator varia de muito denso e com partículas granulares de elevada capacidade de sedimentação, próximas ao fundo (leito de lodo), até um lodo mais disperso e leve, que se posiciona imediatamente acima do leito de lodo, denominado de manta de lodo.

De acordo com Campos (1990) a estabilização da matéria orgânica ocorre em todas as zonas de reação (leito e manta de lodo), sendo a mistura do sistema promovida pelo fluxo ascensional do esgoto e das bolhas de biogás. $\mathrm{O}$ esgoto entra pelo fundo do reator e o efluente deixa o mesmo pela parte superior. Um separador trifásico, localizado abaixo do decantador, garante as condições ótimas para a sedimentação das partículas que se desgarram da manta de lodo. Autilização do processo anaeróbio em dois estágios, com reatores em série, pode propiciar melhor desempenho na remoção de sólidos suspensos orgânicos, incrementando a hidrólise no primeiro reator, melhorando, assim, a remoção de matéria orgânica e a produção do metano no segundo, conferindo maior estabilidade ao sistema de tratamento (2001; Pereira, 2003; Campos, 2006).

Saleh (2003) ao estudar dois reatores operando em série, verificou que houve elevada eficiência na remoção da DQO e na redução dos teores de sólidos em suspensão, possibilitando, nas condições operacionais impostas, alcançar valores médios entre $84 \%$ e $86 \%$,respectivamente ao estudar o desempenho de reatores do tipo UASB de um e dois estágios, tratando águas residuárias de suinocultura, concluiu que o sistema de dois estágios foi eficiente na remoção de DQO e de sólidos suspensos.

Tendo em vista todos os aspectos expostos, objetivou-se, com a realização desta pesquisa avaliar o desempenho na remoção de matéria orgânica, originada de dejetos de suíno, utilizando dois reatores anaeróbios funcionando em série, sendo o primeiro um reator anaeróbio compartimentado (RAC) e, em seqüência, um reator anaeróbio de manta de lodo (UASB).

\section{MATERIAL E MÉTODOS}

O conjunto experimental era composto por um sistema de tratamento de efluentes instalado no setor de Suinocultura. Coordenadas geográficas $21^{\circ} 13^{\prime} 55^{\prime}$ ' de latitude sul e $44^{\circ} 58^{\prime}$ 12 " de longitude oeste e $885 \mathrm{~m}$ de altitude. O clima, segundo classificação de Köppen, é do tipo Cwa, temperado com verões quentes e úmidos e invernos secos e frios.

A concepção das unidades de tratamento utilizadas nesta pesquisa é proveniente de vários estudos em escala laboratorial realizados no Departamento de Engenharia da universidade Federal de Lavras (Campos et al., 2005a; Campos et al., 2005b; Campos et al., 2006).

A granja de suínos possuía em torno de 400 animais adultos. O efluente era conduzido por gravidade até a caixa de areia, por meio 
de tubulações de $200 \mathrm{~mm}$ de diâmetro, e nesse percurso existiam seis poços de visita para desobstrução e vistorias. Nem todo efluente líquido era destinado ao peneiramento, sendo parte dele conduzido para uma lagoa de infiltração.

Para tratamento preliminar do efluente, foi utilizada uma caixa de areia (desarenador), com a finalidade de reter materiais abrasivos (areia, sites e outros). Nessa unidade, foi instalado um vertedor triangular de Thompson, construído em ardósia, para a medição da vazão, cuja abertura triangular possuía $19,5 \mathrm{~cm}$ de base por $9,5 \mathrm{~cm}$ de altura. As medidas da caixa de areia eram de 2,20 m de comprimento e $0,53 \mathrm{~m}$ de largura, e a calha de Tompson estava instalada a $1,68 \mathrm{~m}$ do início da caixa de areia. Na seqüência, o efluente era conduzido a uma peneira estática com malha em aço inox. O comprimento linear da peneira estática é de $1.180 \mathrm{~mm}$. A caixa suporte da peneira foi construída em PVC com chapa de 8 $\mathrm{mm}$ e a alimentação se dava pela parte superior, onde existia um pequeno reservatório por onde o esgoto afluente era lançado e vertia por cima da malha de aço em perfil curvo, permitindo a separação da parte líquida e sólida. A parte líquida era conduzida, pelos orifícios da peneira, para dentro da caixa de PVC, cuja estrutura suportava a malha da peneira e, pela parte inferior desta caixa, o líquido era transportado para o tanque de acidificação e equalização (TAE) e, posteriormente, bombeado para o sistema de tratamento. O percentual de sólidos retidos na superfície da peneira estática escorria gravitacionalmente para as partes inferiores desta e, após acúmulo, se precipitava no leito de drenagem, construído com pedra de mão, brita 1 , brita 0 , areia e tijolos, por onde a parte líquida, ainda presente nos sólidos precipitados, sofria percolação. A eficiência da peneira estática foi avaliada com base na remoção de sólidos totais, representados em porcentagem. As amostragens para essas determinações analíticas ocorreram durante todo o período de funcionamento do sistema de tratamento.

O resíduo líquido infiltrado no leito de drenagem era conduzido a uma caixa de recepção construída de tijolos cimentados e argamassados e, posteriormente, recalcado para o TAE com capacidade de $8.500 \mathrm{~L}$, por uma bomba marca Anauger, com potência de $370 \mathrm{w}, \mathrm{Q}_{\min }=0,55$ $\mathrm{m}^{3} \mathrm{~h}^{-1}, \mathrm{Q}_{\max }=1,97 \mathrm{~m}^{3} \mathrm{~h}^{-1}$ e $\mathrm{h}=637,7 \mathrm{kPa}$, para a acumulação do efluente líquido peneirado. Após a reunião dos efluentes no TAE, o efluente era recalcado por meio de uma bomba Nemo, marca Netzsch, modelo NM015by01L06b, para o sistema de tratamento piloto. O referido bombeamento era controlado por um inversor de freqüência da marca WEG-CFW08 com 12 entradas, o qual proporcionava variação da vazão com precisão, podendo-se, assim, modificar a carga a ser aplicada às unidades de tratamento (figuras 1 e 2).

O efluente final, já tratado, era enviado a um reservatório de fibra de vidro de 3.000 litros e, posteriormente, recalcado por uma motobomba com potencia de $490 \mathrm{w}, \mathrm{Q}_{\text {máx. }}=10,4$ $\mathrm{m}^{3} \mathrm{~h}^{-1}, \mathrm{P}_{\text {máx }}=264,9 \mathrm{kPa}$ e $\mathrm{P}_{\text {mín }}=117,7 \mathrm{kPa}$ para um outro reservatório de 1.000 litros, a fim de ser utilizado para fertirrigação. O efluente líquido dos dejetos de suínos era bombeado continuamente para os reatores, sendo o primeiro reator do tipo RAC, com três câmaras, cujo fluxo, em cada um dos compartimentos, era ascendente. Esse reator foi construído de tijolo maciço e argamassa forte, revestido internamente com manta asfáltica, e coberto com uma camada de fibra de vidro. O primeiro compartimento do RAC possuía volume de 2.180 litros, o segundo de 1.996 litros e o terceiro de 1.906 litros, correspondendo um volume total de 6.082 litros (figuras 3 e 4). O fluxo ascendente em cada compartimento era equalizado por meio de calhas niveladas, construídas com vários vertedores triangulares, cuja finalidade era proporcionar um fluxo homogêneo em cada um dos compartimentos, a fim de se evitar zonas mortas e curto-circuito 
hidráulico. Nessa unidade, procurou-se propiciar condições adequadas às primeiras etapas das reações anaeróbias, hidrolização e acidificação, acelerando a metanogênese na unidade posterior (UASB).

Para o acompanhamento quantitativo e qualitativo do perfil do lodo acumulado, foram colocados, em cada compartimento, quatro registros em PVC (pontos de amostragem) para as coletas das amostras de lodo.

$\mathrm{O}$ efluente do reator do tipo RAC era encaminhado por gravidade para o reator anaeróbio de fluxo ascendente de manta de lodo (UASB), com volume útil de 3.815 L (figuras 5 e 6). Na parte superior do reator foi instalado um separador trifásico, utilizandose meia manilha construída de concreto vibrado, com formato semicircular, por meio da qual o biogás produzido era coletado e conduzido, por meio de tubos PVC de 12,5 $\mathrm{mm}$ de diâmetro, ao equalizador de pressão, e posteriormente queimado. O separador trifásico exercia também a função de um defletor de sólidos. Quando da ascensão de partículas sólidas (lodo) junto com bolhas de biogás, o choque das mesmas com as paredes do separador trifásico fazia com que se separassem, obrigando os sólidos a retornarem, por sedimentação, para o fundo do reator. Esse processo de retenção de sólidos era fundamental para a formação da manta de lodo, aumentando significativamente a eficiência operacional dessa unidade.

Uma vez que não se utilizou inóculo, a partida do sistema foi baseada em parâmetros de sedimentabilidade. As cargas superficiais aplicadas foram bastante baixas, tanto para o RAC, como para o UASB (1,2 e 1,5 $\left.\mathrm{m}^{3} \mathrm{~m}^{2} \mathrm{~d}^{-1}\right)$, respectivamente. Em termos comparativos, esses valores, podem chegar a valores maiores que $30 \mathrm{~m}^{3} \mathrm{~m}^{-2} \mathrm{~d}^{-1}$ (Campos, 1990). Os baixos valores auxiliaram grandemente na retenção de sólidos nas unidades de tratamento. Os tempos de detenção hidráulica foram de 53 horas e 33h30min, para o RAC e o UASB, respectivamente. As cargas hidráulicas aplicadas foram 0,45 e $0,72 \mathrm{~m}^{3} \mathrm{~m}^{-3} \mathrm{~d}^{-1}$.

Este mesmo procedimento de partida sem inóculo foi adotado em outras pesquisas laboratoriais (Campos et al., 2005a; Campos et al., 2005b; Saleh, 2006 e Campos, 2007). Apesar de apresentarem valores semelhantes, a carga superficial e a velocidade ascendente apresentaram diferenças nas respectivas unidades. A carga superficial refere-se ao volume de dejetos aplicados diariamente (no reator) por unidade de área. Já a velocidade ascendente representa a relação entre a vazão afluente e a seção transversal do reator. A carga orgânica volumétrica (COV) é definida como sendo a quantidade de matéria orgânica (em termos de DQO ou DBO) aplicada diretamente ao reator, portanto, multiplicada pela vazão do afluente, e dividida pelo volume útil do reator (Campos et al., 2005b). Já a carga orgânica biológica (COB) é fornecida em função da quantidade de matéria orgânica (em termos de DQO, DBO) multiplicada pela vazão afluente e dividida pela massa de sólidos voláteis totais (SVT) presentes na manta de lodo das unidades (Campos, 2006).

O processo de amostragem deu-se de forma pontual, apresentando grandes variações. Os parâmetros analisados obedeceram a uma rotina preestabelecida. Em cada uma das unidades de tratamento foram coletadas amostras, utilizandose, para isso, frascos plásticos. Assim, o efluente de uma unidade era o afluente da unidade seguinte.

Foram feitas determinações da eficiência na remoção de matéria orgânica, por meio da análise de $\mathrm{DBO}_{5}$. Os pontos monitorados foram: peneira estática, TAE, RAC, UASB e o tanque de armazenamento do efluente final. As análises foram semanais, em algumas ocasiões. Somente parte dos resultados obtidos pôde ser utilizada e explicitada de forma gráfica. A eficiência de todo o sistema foi obtida por meio dos resultados da $\mathrm{DBO}_{5}$ do efluente do tanque 
de armazenamento final e o afluente da caixa de entrada, após o vertedor triangular. Todas as análises foram realizadas no Laboratório

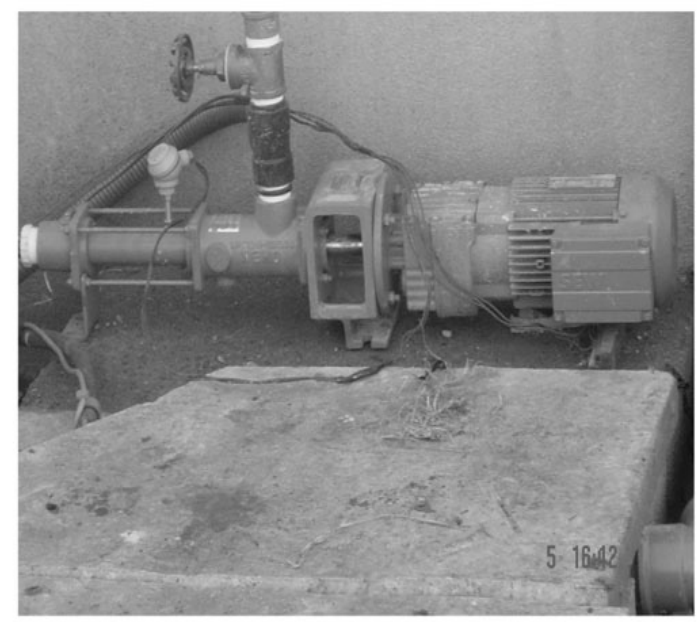

FIGURA 1 - Bomba (NEMO) de Análise de Água do Departamento de Engenharia (LAADEG) e no Laboratório de Águas do Departamento de Solos da UFLA,

\section{Inversor de frequência}

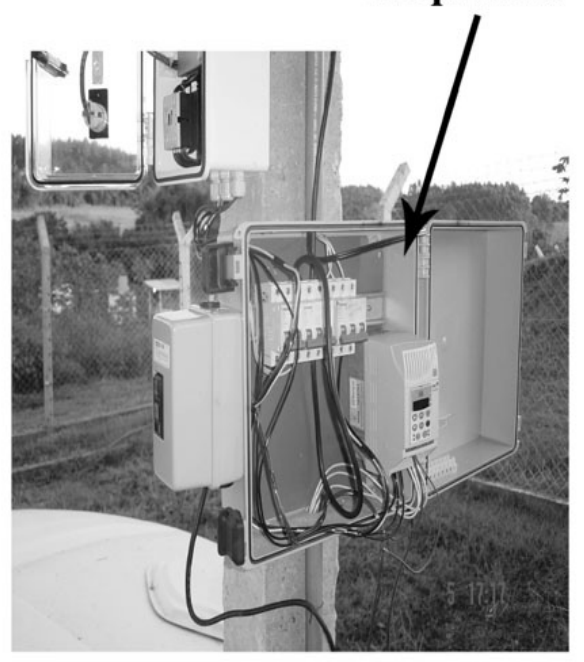

FIGURA 2 - Inversor de freqüência

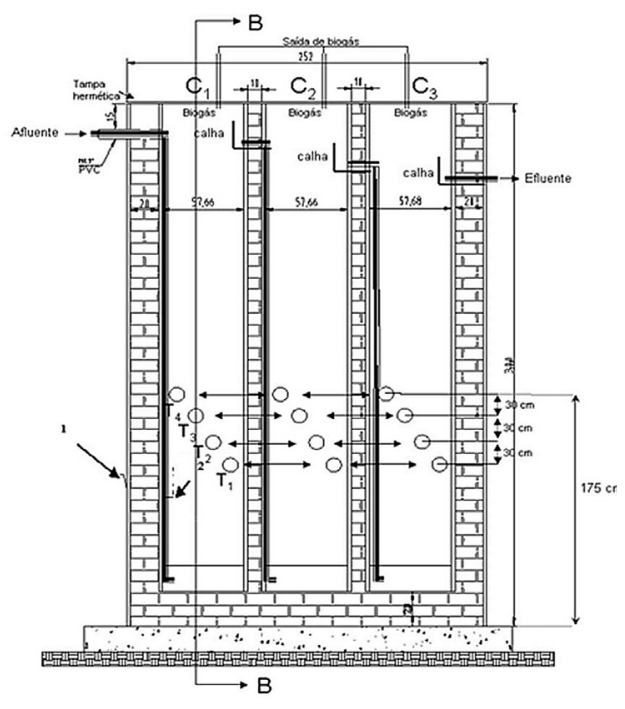

Figura 3. RAC - corte longitudinal

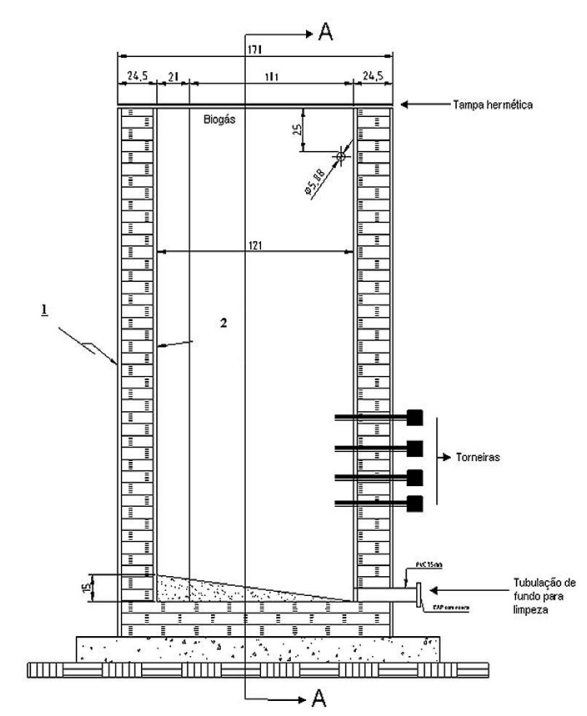

Figura 4. RAC - corte transversal 


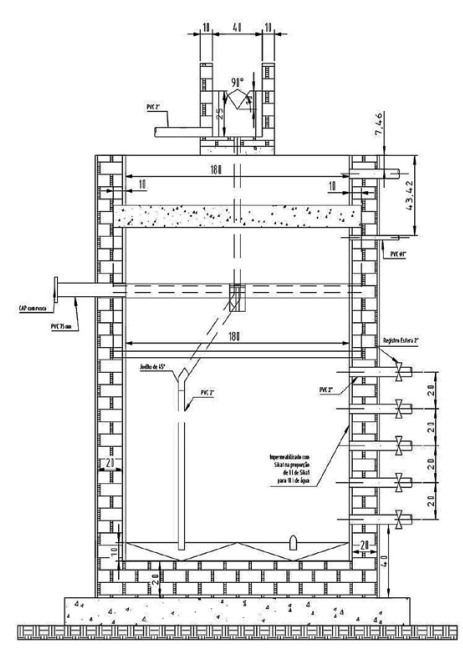

Figura 5. Reator UASB - corte longitudinal

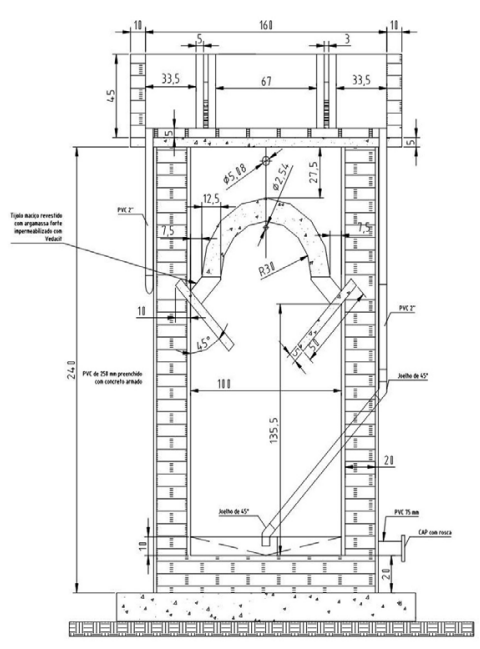

Figura 6. Reator UASB - corte transversal

\section{RESULTADOS E DISCUSSÃO}

Durante o período experimental, foi observada grande variação da vazão em função da lavação manual das baias. As lavações eram realizadas por meio de mangueira convencional a baixa pressão e excessiva vazão, o que causou gastos exagerados de água e, conseqüentemente, picos de vazão. $\mathrm{O}$ valor médio da vazão ao longo do experimento foi de $0,378 \mathrm{~L} \mathrm{~s}^{-1}$. A vazão do sistema era mantida por meio de bombeamento e a vazão excedente conduzida para uma das lagoas de infiltração. Ocorreram variações nas cargas orgânicas volumétricas e biológicas devido à flutuação da concentração da $\mathrm{DBO}_{5}$, uma vez que a vazão nas unidades de tratamento era mantida constante. Outro aspecto importante a ser mencionado é que as amostragens instantâneas também podem ter influenciado no cálculo das cargas, já que, em certas condições, a unidade analisada poderia estar, num dado momento, liberando sólidos em seu efluente, fenômeno este denominado varredura, mascarando a determinação quantitativa das cargas (Campos, 2006).

O segundo compartimento do RAC teve maiores valores de COB do que os demais, possivelmente devido à menor quantidade de sólidos voláteis totais (SVT) presente nesse compartimento. Pôde-se observar que o reator UASB apresentou uma $\mathrm{COB}$, em função da $\mathrm{DBO}_{5}$, mais homogênea ao longo de todo o período experimental, quando comparada aos demais compartimentos do RAC, levando a crer que o RAC auxiliou na equalização da COB ao longo de cada uma das suas câmaras, permitindo que o reator UASB sofresse menos alterações. $\mathrm{O}$ reator UASB, no período compreendido entre 3 a 9 de maio, mostrou grande incremento, passando de valores menores do que 2 para valores próximos a $8 \mathrm{~kg}$ DQO $\mathrm{kg} \mathrm{SVT}^{-1} \mathrm{~d}^{-1}$, demonstrando assim que, uma vez que a vazão foi mantida constante, a concentração de DQO efluente sofreu aumentos excessivos. A eficiência na remoção da $\mathrm{DBO}_{5}$ na peneira estática variou de $20 \%$, passando, posteriormente, para um valor negativo, em torno de $-20 \%$ e, em uma terceira etapa, em torno de $75 \%$, mostrando grande variação nos valores amostrados. $\mathrm{O}$ valor da eficiência negativa sugere que, os sólidos no efluente eram maiores que no afluente durante a amostragem e que ocorreram condições adversas, uma vez que a 
peneira estática remove apenas fisicamente a matéria orgânica. O valor de $75 \%$ está bastante elevado, devido possivelmente, ao processo de amostragem, levando à conclusão de que mais análises deverão ser realizadas com a finalidade de caracterizar a remoção física da matéria orgânica nessa unidade.

A separação inicial foi muito importante porque, além de facilitar a operação das demais unidades de tratamento, reduziu os riscos de entupimento das tubulações de recalque e dos tubos gotejadores utilizados na fertirrigação de feijão-vagem. Além disso, o peneiramento pode ter colaborado intensamente no sentido de impedir a redução da atividade metanogênica do lodo, corroborando com as afirmações feitas por Ramirez (2005).

A eficiência de remoção da $\mathrm{DBO}_{5}$ na TAE, reservatório destinado a receber o efluente da peneira estática e do poço de recolhimento do tanque de estocagem do percolado proveniente do leito de drenagem, foi de $20 \%$ a $40 \%$. Tal eficiência ocorreu devido à baixa taxa da carga superficial, fazendo com que os sólidos mais grosseiros que passaram na peneira estática decantassem e fossem removidos. O reator anaeróbio compartimentado (RAC) mostrou, inicialmente, uma elevada eficiência na remoção de $\mathrm{DBO}_{5}$, devido, principalmente, ao efeito de decantação de sólidos em função da baixa carga superficial aplicada ao mesmo. Posteriormente, a eficiência chegou até o valor mínimo, aproximadamente $23 \%$, para, mais tarde, se elevar até $80 \%$ novamente. O reator UASB, ao contrário do RAC, demonstrou eficiência em torno de $45 \%$ durante o início do experimento. Em seguida, porém, manteve-se com certa estabilidade, mostrando uma eficiência próxima de $80 \%$. Posteriormente, apresentou uma queda da eficiência, resultando valores abaixo de $40 \%$. Um dos motivos da diminuição da eficiência está relacionado, possivelmente, com a baixa temperatura ambiente.

A eficiência de remoção de matéria orgânica de todo o sistema, em termos de
$\mathrm{DQO}$ e de $\mathrm{DBO}_{5}$, foi de, aproximadamente, $98 \%$, indicando boa aclimatização durante essa primeira fase, devendo ocorrer ainda uma melhoria considerável à medida que o lodo for melhorado por meio do cultivo, aumentando a sua capacidade de sedimentabilidade e atividade metanogênica, tanto no RAC como no UASB.

Nas figuras 7, 8, 9 e 10 mostramse, respectivamente, o tempo de detenção hidráulico, a carga hidráulica, a carga superficial e a velocidade ascendente em cada uma das unidades do sistema de tratamento. A variação da vazão afluente, o desempenho da curva da bomba Nemo, a carga orgânica volumétrica e a carga orgânica biológica, em termos de $\mathrm{DBO}_{5}$, podem ser vistos nas Figuras 11, 12, 13 e 14, respectivamente.

\section{Demanda bioquímica de oxigênio}

Verificou-se uma oscilação da $\mathrm{DBO}_{5}$ do efluente do UASB de 82 a $680 \mathrm{mg} \mathrm{L}^{-1}$, com média de $381 \mathrm{mg} \mathrm{L}^{-1}$. Este valor foi $120 \%$ maior que a média encontrada por Campos et al. (2005b) e Carmo et al. (2004), com TDH de 30 horas. O tempo de detenção hidráulica adotado foi de 33 horas, todavia, o sistema, por estar na fase instável durante a partida e por não ter sido realizada inoculação, apresentou grande variação, influenciada, inclusive, pela carga orgânica (Campos et al., 2005a).

\section{Demanda química de oxigênio}

Ocorreu uma oscilação da DQO do efluente do UASB de 707 a $3.087 \mathrm{mg} \mathrm{L}^{-1}$. O valor médio de $1.897 \mathrm{mg} \mathrm{L}^{-1}$ foi muito semelhante ao encontrado por Campos et al. (2005b) em trabalho realizado com dejetos de suinocultura em escala laboratorial $\left(1.755 \mathrm{mg} \mathrm{L}^{-1}\right)$. Fernandes \& Oliveira (2006) encontraram valores de DQO total por volta de $500 \mathrm{mg} \mathrm{L}^{-1}$ para o efluente do UASB operando com TDH de 13 horas. No caso do presente trabalho, o TDH foi de 33 horas, o que permite concluir que o sistema ainda estava em fase de aclimatação. 

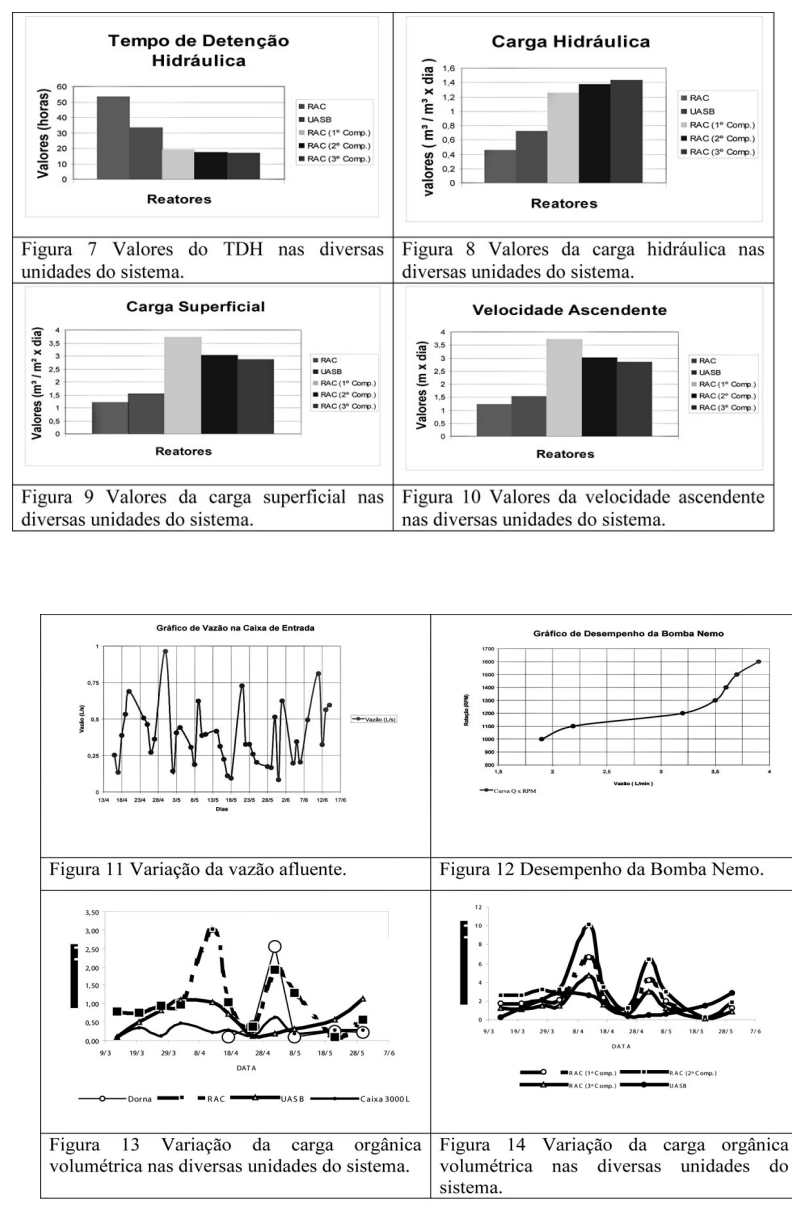

\section{CONCLUSÃO}

O sistema de tratamento piloto, incluindo o tratamento preliminar (peneiramento), o TAE, que também agiu como um tanque de sedimentação, as duas unidades anaeróbias (RAC e UASB), bem como a caixa de armazenamento do efluente final, se mostrou apto quanto à eficiência na remoção de sólidos, permitindo boa remoção de matéria orgânica do sistema.

$\mathrm{O}$ experimento demonstrou nitidamente aumento progressivo, tanto da condutividade elétrica (CE) como dos sólidos dissolvidos totais (SDT), à medida que a água residuária de suínos passava de uma unidade para a outra. Os parâmetros CE e SDT variaram de 1,92 a $3,33 \mathrm{dS} \mathrm{m}^{-1}$ e de 1.226 a $2.133 \mathrm{mg} \mathrm{L}^{-1}$, respectivamente, demonstrando que, durante o tratamento, os sólidos presentes migraram para sólidos dissolvidos.
O processo aplicado para a partida dos reatores se mostrou eficiente, mostrando boa retenção de sólidos e, portanto, dever ser dada continuidade, a fim de que o sistema passe da condição de instabilidade (transiente) inerente à partida para a condição de estabilidade, produzindo um efluente final com parâmetros mais adequados capaz de atender tanto a legislação vigente como ainda ser utilizado sem restrições na fertirrigação.

\section{AGRADECIMENTOS}

Os autores agradecem à Fundação de Amparo à Pesquisa do Estado de Minas Gerais (FAPEMIG), pelo apoio financeiro na execução das unidades piloto. Ao Laboratório de Análises de Água (LAADEG), do Departamento de Engenharia da UFLA, pelo suporte técnico e execução das análises físico-químicas.

\section{REFERÊNCIAS BIBLIOGRÁFICAS}

APHA - AMERICAN PUBLIC HEALTH ASSOCIATION - Standard methods for the examination of water and wastewater. $20^{\text {th }}$ ed. New York. 1998.

CAMPOS, C. M. M. Physical aspects affecting granulations in UASB Reactors. 1990. 459 p. Thesis (PhD) - University of Newcastle upon Tyne, Newcastle.

CAMPOS, C. M. M; DAMASCENO, L. H. S.; MOCHIZUKI, E.T.; BOTELHO,C.G. Avaliação do desempenho do reator anaeróbio de manta de lodo(UASB) em escala laboratorial na remoção da carga orgânica de águas residuárias da suinocultura. Revista Ciência eAgrotecnologia, Lavras, v. 29, n. 2, p. 390-399, mar./abr. 2005 a.

CAMPOS, C. M. M; MOCHIZUKI, E.T.; DAMASCENO, L. H. S.; BOTELHO,C.G. Avaliação do potencial de produção de biogás e da eficiência de tratamento do reator anaeróbio de manta de lodo(UASB) alimentado com 
de suínos. Revista Ciência e Agrotecnologia, Lavras, v. 29, n. 4, p. 848-856, jul./ago. 2005 b.

CAMPOS, C. M. M.; CARMO, F. R.. ; BOTELHO, C. G. Desenvolvimento e operação de reator anaeróbio de manta de lodo (UASB) no tratamento dos efluentes da suinocultura em escala laboratorial. Ciência e Agrotecnologia, Lavras, v. 30, n. 1, p. 140-147, jan./fev. 2006.

CAMPOS, C.M.M. Estudo da Tratabilidade de Dejetos Suínos. Relatório Técnico Final - Fundação de Amparo à Pesquisa de Minas Gerais - FAPEMIG: TEC 1550/03. Lavras, 2007. 115p.

CHERNICHARO, C.A. L. Princípios do tratamento biológico de águas residuárias Vol. 5. Reatores anaeróbios, DESA-UFMG, $1^{\mathrm{a}}$ edição. 245 p. 1997

LIER, J.B. Van; TILCHE, A.; AHRING, B.K.; MACARIE, R.; DOHANYOS, M.; HULSHOFFPOL, L.W.; LENS, P.; VERSTRAETE, W. New perspectives in anaerobic digestion. Water Science Technology, Kidlington, v.43, n.1, p.1-18, 2001.
OLIVEIRA, R.A.de. Efeito da concentração de sólidos suspensos do afluente no desempenho e características do lodo de reatares anaeróbios de fluxo ascendente com manta de lodo tratando águas residuárias de suinocultura. 1997. 359 f. Tese (Doutorado em Hidráulica e Saneamento) - Escola de Engenharia de São Carlos, Universidade de São Paulo, São Carlos, 1997a.

RAMIRES, R. D. Produção de metano e remoção de matéria orgânica, nutrientes e microrganismos patogênicos em reatores anaeróbios de fluxo ascendente com manta de lodo (UASB) em dois estágios tratando águas residuárias de suinocultura. 2005. 136 p. Dissertação (Mestrado em microbiologia agropecuária) - Faculdade de ciências agrárias e veterinárias- UNESP, Jaboticabal.

SALEH, B. B. Parâmetros cinéticos de reatores anaeróbios de manta de lodo(UASB) operando com efluentes líquidos agroindustriais. 2003. 66 p. Dissertação (Mestrado em Construções Rurais e Ambiência) - Universidade Federal de Lavras, Lavras, MG. 